\title{
Characteristics Analysis of Chinese college students' leisure sports behavior
}

\author{
Huiqiao Duan ${ }^{1, \text { a }}$ \\ ${ }^{1}$ Wuhan Business University, Wuhan, Hubei Province, China \\ a635102151@qq.com
}

Keywords: Leisure sports, Chinese college students, Casual Living, Sports behavior

\begin{abstract}
Leisure sports advocating healthy lifestyle, pay attention to the all-round development of man, and the contemporary college students not only should have a good professional qualities to adapt to all kinds of society needs, but also should notice the leisure time of life and develop themselves both in the work part and leisure part. Leisure sport is the fruit of human material and spiritual civilization. It is a new kind of life style and reflects the social civilization. The university students should take part in leisure sport, which can promote body health, adjust mood, promote intelligent development, increase entertainment projects and improve social skills. Therefore, the college students should cultivate leisure sport proverbs and actively participate in leisure sports, which is very important.
\end{abstract}

\section{Introduction}

Leisure sports mainly refers to people in the spare time using a variety of methods and techniques of physical and mental exercise, carry out a variety of forms, the content variety of entertainment and recreation activities, it through the consumption of time and energy to adjust body and mind, and in which the emotional experience [1]. Leisure sports is a way of life of modern civilized society and means of communication, people in the leisure way actively, happily engaged in some kind of physical activity, in order to realize self-value, improve the quality of life.

\section{The characteristics of leisure sports}

Leisure sport is a component part of social sports. Refers to the people in their spare time to improve their physical and mental health, enrich and create life interest, improve themselves, for the purpose of physical exercise activities [1]. Live in a rich content and strengthen the interpersonal relations, and promote social and personality formation has important significance and function, with its unique advantages.

The diversity of the content and nature. Leisure sports can be either collective activity, can separate activity,it can play an important role in the movement, and movement in the nature, and can be done in the beautiful music melody alone or group activities [1]. There are many different kinds of sports: there are predominantly land leisure sports, such as walking, running, yangko, swing, play gyro, brain-storming tennis, swimming, travel, bowling, family fitness, mountain climbing, hiking, rock climbing, mountain biking, directional cross-country, outdoor hiking, exploration, rope skipping, climbing stairs, badminton, basketball, volleyball and soft volleyball, skating, skiing, skateboarding, pulleys, etc.. Have given priority to with water leisure sports, such as surfing, swimming, skiing, boating, sailing, diving, fishing, drifting. that is given priority to with airspace of leisure sports, such as the glide, parachuting, balloons, etc... All you can do what you want, choose what you love, makes more flexibility in the form of exercise.

Choose the freedom of movement time. Leisure sports have a wide range of adaptability, different mood and emotional state, and even different personality and temperament of the people can be obtained from a leisure sports own satisfaction; And recreational sports in time is very loose, casual, can use the break time to study, can also use a staggering scattered time, still can use morning and night time to rest. Time can be long or short, depends on own strength, interest, busy and idle of 
the specific circumstances [2]. As long as there is the desire of the fitness, can at any time according to their own intend to engage in relaxing exercise.

Low demand of sports venues. Engaged in the leisure sports low requirement to the ground, regardless of the size, location, where the room, balcony, or the steps, the side of the road, under the tree or building space; There is the mountain, river, or the field, garden, park or playground, etc., is not the fitness field, for people's fitness provides a rich and colorful sports fitness sites, making fitness activities more convenience [2].

Leisure sports relaxing, moderate energy consumption. Another characteristic of recreational sports is relaxed and cheerful, sports load is light, not the pursuit of the great physiological load of exercise, physical consumption is measurable, for fitness all the tissues and organs function can adjust the use, can play a good make the exercisers in leisure sports in a fun, get the feeling of the physical and mental pleasure [2]. In the process of exercise, exercisers can don't shy away from sports technology of ignorance, you don't have to for the action of stupidly and shy, do not have to worry about the outcome for the sport. Still can make the exercisers to forget trouble, dug in addition to all the unhealthy emotional impact, this process not only is the process of exercise, and is a process of purify the mind, is the process of eliminating stress.

\section{Chinese college students' leisure sports life and its influencing factors}

According to the survey of contemporary college students is one of the most time consuming leisure activities is given priority to with static, reading books, watching movies, surfing the Internet, computer and TV, chat, etc., other loiter about, gossip, sorting waste of time, girls prefer shopping, men prefer computer games, lack of leisure time has positive significance to planning, lack of activity in dynamic activity, is not in conformity with the youth leisure direction [3]. The college students themselves have the following categories:

Don't have enough money and time to leisure. Contemporary college students is generally accepted that leisure should be placed on learning, even on a part-time job, think that leisure is raffish. Survey of the vast majority of students believe that recreational factor is money the first obstacle, club activities organized by the school is mainly introduced the student association of youth, the lack of funds, students want to join the group of sports must be paid, which for the most part dampened the enthusiasm of them, so have to do most of the students think that leisure is a rich man [2]. And the time factor, a large proportion of people claim to all don't have time to go to the leisure sports life trivia, but actually reflects the students don't know their spare time should be used to learn or recreational ambivalence, is to doubt of the value of leisure - always think there is no need to take the time to study to leisure sports.

Leisure activity species is not rich, no proper sports. College students expect more leisure activities is dynamic and passion of youth, such as hiking, camping, hiking, party, fitness, etc. But due to constraints such as space, traffic, schools often provides five kinds of sports, and the limit of the student to the leisure sports, there is a lot of students to "no suitable project" as an excuse to refuse.

\section{The significance of the college students' behavior development of leisure sports}

Leisure sports in physical activity is given priority to, the activists actively under the domination of consciousness, make the body's physiological and psychological produce different degrees of positive change [3]. So I can transfer the brain's nervous excitement, accelerate the recovery of physical fatigue, implement the "enthusiasm" rest, so as to improve and improve college students' learning efficiency, make the person mind, quick thinking; it can also promote the improvement of the human body internal organs in the body and the improvement of function; Can also improve the body's ability to adapt, immunity and resistance to external damage, to adapt to the society in the future to engage in productive labor, living learning needs.

Leisure sports not only can make college students more outdoor activity, close to nature, the activities of the body, stretches the physique, but also can more easily provide a relaxed, cordial and pleasant communication environment. Exchanges between students more often so that they can 
encourage each other in the activities, equal communication, helps to establish a good interpersonal relationship.

Contemporary college students should not only face a daily reality problems such as study, life, social communication, at the same time, you have to face the increasingly severe employment pressure. Sport as an important part of the curriculum in colleges and universities, to promote the development of college students' physical and mental health has a special role [4]. According to domestic and foreign related research shows that the long engaged in physical exercise can effectively ease the mental pressure, relieve mental tension, adjust the intensity of emotional response. Helps to cultivate the students' unity cooperation, have the courage to endure hardship, self-control, patience, will quality, flexible, proactive, in the face of difficult to calm in the face of pressure optimistic bold, finally able to quickly adapt to the environment, into the environment. So apparently, leisure sports activities in the student life environment and the living content at the same time, cultivate the group consciousness and skills, improve the social adaptation ability.

\section{The development of leisure sports in colleges and universities}

University education on students' professional outside, outside of the classroom education, has been in a subordinate, and even neglected. Faced with plenty of leisure time, some students or helpless, spiritual feeling lonely emptiness; Or in muddled away, waste of youth. The extracurricular activities of the university, not widely mobilize the participation of all students, or because of coercion and force, the significance of the leisure and freedom dissimilation burden to the other students.

Enlightenment science and leisure consciousness, cultivate free, cultural life concept. Have leisure is one of the oldest human dream, the human dream out of the endless toil, follow one's inclinations, do a loved to readily state, to find what you love. The process itself is not only enjoyable, but also the meaning of life [4]. The university leisure education is to establish a sound leisure values, enlighten the scientific leisure consciousness, emphasize the very essence of leisure two characteristics, namely free optional and no external goal only pay attention to inner satisfaction. Free optional leisure activities, can be in a state under pressure, cheerful, can coruscate inner love. Leisure activities without external goal, only pay attention to leisure process of inner satisfaction, truly people-oriented.

Fully protect the rights of students' leisure, extension of comprehensive quality education system. Leisure emphasizes freedom of choice, the university compulsory or half the compulsory club activities is not the real meaning of leisure activities. University should system builds the all-round quality education system and establish the correct leisure values, elegant artistic atmosphere, strong academic atmosphere, the conditions of the freedom of choice for students [4]. All kinds of education resources and make full use of the university, for example, social and cultural resources, let students enjoy the freedom of choice to enjoy these resources power, recognition of leisure skills and special skills, flexible setting quality training system in an all-round way.

Investment, the establishment of leisure skills guidance and training system. Attaches great importance to the professional education in the university courses, elective courses to impart knowledge and jobs to make a living skills course is given priority to, and students' personal interests, hobbies and personality of the course is lack [5]. So you need to invest capital, the opening of a leisure skills of elective courses, or free training classes, computer classes for college students in the form of music, dance, skills training, travel, social activities, etc. For students' extracurricular activities and games free organization, also should be put into special funds to support.

Leisure activity form rich and innovation, encourage the development of personality. Play the schools campus culture characteristics and appeal to rich and innovative form of leisure activity, especially the young people love the dynamic state of leisure, such as sports and all kinds of social.

But the survey shows, nowadays, many students ignore sports leisure. Schools should provide various conditions to encourage college students to participate in sports, exercise in the exercise, show youthful vitality, blend in interpersonal communication. 
In addition, less social activities at the university of our country, and less formal. Foreign universities often have a ceremony, party, such as formal social occasions, college students through participation, cultivating social etiquette, form the elegant and civilized behavior, expand your social circle, shaping personality.

Improved cultural facilities in leisure, leisure places. University to provide a rich social practice base, plenty of study area, sports ground, have a high quality service of the library, computer room, open the science museum, etc., To create a strong academic, artistic atmosphere and elegant leisure environment, it is improve the hardware of leisure education, especially to strengthen the construction of the campus sports facilities and related departments to try to students' needs into consideration, build appropriate fitness venues and basketball court, ensure the normal order of the majority of students' leisure sports, in fact, as long as you can experience the feeling of happiness, a lot of places, such as air pure and fresh, the trees could be the leisure sports [5].

\section{Summary}

Leisure sports on college students' physical and mental health, improve the quality of learning, life, play an important role. This positive sports education in colleges and universities should make full use of recreational sports, health, civilization and scientific way of leisure, guide and help students to participate in sports, with positive attitude to grasp myself, adjust the self and external connection, so as to improve students' ability to adapt to society, to improve the physical and mental health of college students; At the same time, college students should take an active part in leisure sports activities, enhance physical and mental health level of self-awareness, establish leisure sports health perspectives.

\section{References}

[1] F. Zheng, Leisure sports and the physical and mental health of college students, Bijie college journal, 2007, vol.3, pp.14-17.

[2] R.W. Liang, The investigation and analysis of restricting factors of Chinese college senior student leisure sports , China's sports magazine, 2014, vol.12,pp.33-36.

[3] K.Y. Ji, Expansion of colleges and universities sports curriculum to promote students' physical and mental health, colleges and universities to carry out the experimental research, Field survival training school sports in China, 2003, vol.21, pp. 73-76.

[4] Y.W. Liu, Quality education under the vision of the university leisure education, Higher education research, 2009, vol.1, pp.26-30.

[5] G.F. Wang, The development of leisure sports in China, Education theory research, 2012, vol.4, pp.42-47. 